\title{
A study of aspects of structural design based on application of complete modular units
}

\author{
Angelina Rybakova* \\ Moscow State University of Civil Engineering, Yaroslavskoe shosse, 26, Moscow, 129337, Russia
}

\begin{abstract}
In the middle of the 20th century, technical progress allowed to maximize the size of building units, which has led to the advent of new industrial construction systems and increased construction progress rates. However, today the problem remains not completely solved and is still a vexed one. Prefabrication is not widely used, though many structural design experts predict its widespread rollout in the near future. It makes it necessary to find out the obstacles in the way of further development. The purpose of this work is to study prefabrication aspects. The objective of the study is identification of fundamental attributes common to complete modular units (the ones that include equipment and furnishings). The improvement of such aspects is meant to drastically increase design quality. The paper envelops the basic concepts of prefabrication, describes characteristics of complete modular units and analyzes the prefabrication algorithm taking into account existing BIM (Building Information Modeling) software.
\end{abstract}

\section{Introduction}

Prefabrication of engineering systems is integration of various complex standard and nonstandard assemblies with varying characteristics and parameters using a number of preselected types and standard sizes of units.

A modular unit is an autonomous and ready-to-install product. [1] Modular units make up complex systems through connection, disconnection, and replacement for the purpose of creating new complexes with different components and characteristics.

Prefabrication ensures fast installation, maintainability, serviceability, easy replacement of a unit without the necessity to disconnect other units.

Currently it is gaining popularity in various engineering domains and industries. For each activity, prefabrication has its own characteristics, restrictions and ways of development. Each engineering direction is at its own level of prefabrication development: it is, for instance, rather widespread in shipbuilding, but has limited application in capital construction. The degree of implementation differs from one country to another, China being the today's leader. A great number of high-risers have been built in China with extensive application of modular units and their effective design, and construction is carried out in a very short time frame. [2-4]

\footnotetext{
* Corresponding author: angelinaribakova@yandex.ru
} 
Therefore, it is expedient to make use of foreign experience to increase construction effectiveness, improve and promote prefabrication, and look for new ways of its development and implementation in our country. Studying aspects of structural design and modular building as deep as possible for this end is a prerequisite.

\section{Methods}

\subsection{Principles of Prefabrication}

Designing a major construction project based on prefabrication requires observation of certain principles. These principles can be roughly divided into three levels: the first includes general principles of modular assembly of engineering systems, the second takes in construction principles, and the third level envelops principles based on design features specific to the project to be constructed.

The first level principles include universal provisions that make up the basis of modular design of various types of structures. [5-6] These principles are founded on requirements to constructability and functionality. Generally, the first level principles can be defined as follows:

1. Functional and geometrical compatibility of units;

2. Interchangeability of units;

3. Correlation of sizes and parameters;

4. Classification and systematization of units;

5.Integration algorithm;

6. Possibility of analysis and calculation.

The principles of the second level flow out of the first level taking into account special factors relating to construction operations. Here it is important to consider occurrence of problems, climatic and territorial factors, design tools. The following principles may be referred to the second level:

1. Compatibility of structural units and engineering systems;

2. Maximum use of existing units for prefabrication;

3. Height limitations when using modular units;

4. Maximum use of automation tools for design;

5. Adaptation of software tools for modular design;

6. Differentiation of units in harmony with the climate;

7. Dependence of geometrical and functional parameters on motor vehicle accessibility;

8. Simplification of storage and production;

9. Flexibility of construction management techniques;

10. Energy efficiency;

11. Environmental friendliness of materials;

12. Regular expansion of the modular units' library;

13. Continuous updating of classification and systematization of modular units taking with innovative solutions.

The third level is comprised based on technological features and purpose of the capital construction project. This level can include more principles due to a bigger functional and geometrical variety of projects. [7-9] For some projects some principles can be duplicated across the levels due to technological similarity, some remain purely individual. For systematization of third level principles it is logical to determine directions, which are universal for each group of projects. Such directions can be found, as a rule, in every design specification. Therefore, third level principles can be grouped as follows: 
1. Building footprint area;

2. Gross building volume;

3. Number of tenants / workers;

4.Production capacity;

5. Operating conditions;

6. Engineering purpose.

Together the three levels of principles form a system of requirements to all processes in the life cycle of a capital construction project. Analysis of separate groups of the second and third levels helps to determine a number of non-unique principles that can also be used for traditional (non-modular) design. However, in view of the first level restrictions, the whole set of principles represents a full-fledged system of design requirements within a modular framework. [10]

In spite of the fact that the three levels form a theoretical basis, a system of principles by itself does not suffice for a full modular design development. Therefore, further consideration of the main elements of the prefabrication technology is necessary..

\subsection{The Concept of a Complete Modular Unit}

In construction, a modular unit is a complex structural component, which accumulates in itself properties and characteristics of several construction units. A system of modular units is used for coordination of all structures, interchangeability and multifunctionality of components. For greater efficiency of modular units it is practical to build modular units demanding a minimum of additional on-site involvem.

A complete modular unit is a fully functional construction unit built of various materials with maximum readiness for installation. [11-12] As a rule, such units are made offsite, and then transported to the building site, where they are one by one added to the project structure. A modular unit acquires necessary architectural and structural characteristics, includes engineering solutions, equipment and, if necessary, options for interior and exterior finishing. Designed versions of modular units can be combined to create new designs. One modular unit can be used differently in various construction projects (Fig.1).

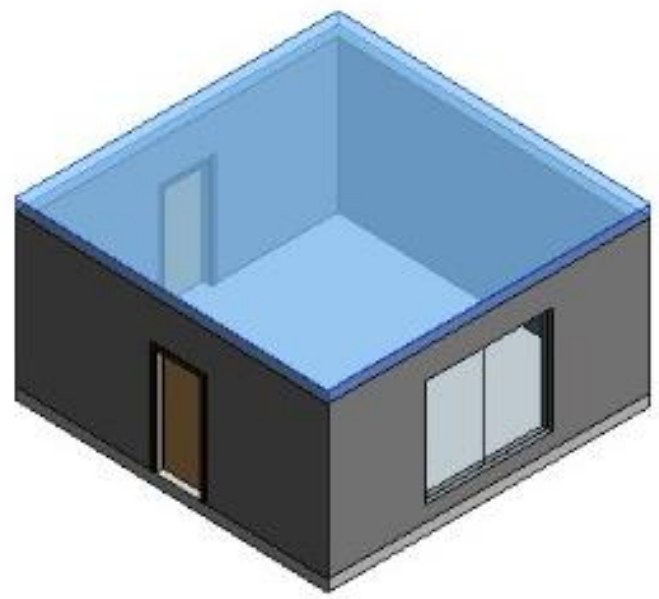

Fig. 1. Example of a complete modular unit.

Prefabrication considerably accelerates construction process, and simplifies it in case of rational installation. However, to maximize advantages it is practical to reduce time for 
development of materials, transportation of units and their rational storage on site. A maximum size of a unit is also limited by factory capacities and restrictions for transportation and installation (sizes and weight). [13-15]

One of the most important points of prefabrication is a quality preliminary design of modular units. For an effective use of modular units, it is necessary to work with a set of units with suitable characteristics at the design stage, these units also having alternative options, classification and systematization. The number of possible layouts, engineering solutions and their implementation depends on quality of units' design and their quantity.

Another important point is availability of tools both for design of modular units and complete project design. In view of the specifics of this principle, it is expedient to use BIM technologies. Nowadays the software suite most suitable for this type of works is Autodesk Revit. Its functionality allows most effective and quick design development, and, if necessary, export of design to another software. [16] It is supposed that for each unit in Autodesk Revit a Revit-family with necessary geometrical and engineering characteristics (the main construction three-dimensional unit in Revit) will be devised. The final BIM model of a design will be an integrated complex of families of modular units. Each modular information model will be one of the possible combinations in modular units' library (Fig. 2).

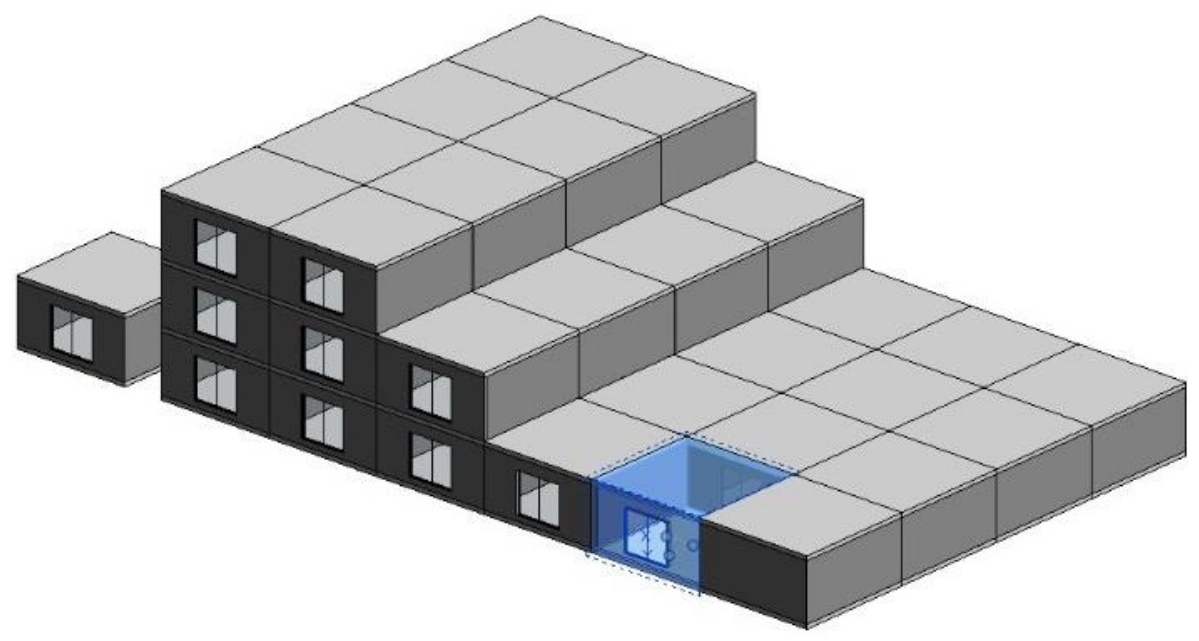

Fig. 2. Building of information model in Autodesk Revit.

Maximization of number of BIM modular units is the basis for a big number of potential alternative options of BIM models of a project. Effective modular design requires simultaneous improvement of classification and systematization of units, and library expansion. Meanwhile, one of the most important aspects of quality modular design is design algorithm. A design process based on the use of complete modular units differs considerably from traditional non-modular designing. This intensifies modernization of the general design algorithm. [17-18]

\subsection{Modular and Traditional Designing}

Modular designing is inherently different from traditional designing processes. The differences make up the theoretical basis for advantages of modular efficiency. The decision to use modular units has to be made at the initial stage. Therefore, design processes differ from the beginning of concept development and to the commissioning or tear down by all 
participants and experts. Corresponding significant changes in designing procedures engender a number of fundamental differences.

1. The customer, general contractor and all project team members begin to cooperate closely at earlier stages. Development of design solutions, analysis of options and decisionmaking are restricted by the principle of modularity. At the same time, new designing ways and methods appear.

2.Design tools alone do not suffice, it is necessary to have a library of modular units. As designing in general can be reduced to selection and combination of blocks, there must be a sufficient quantity of them. Classification and production capabilities are also important.

3. Preliminary thorough coordination of basebuild and engineering systems is crucial for prevention of clashes. [19-20] In traditional design correction of layout or placement of facilities is allowed, while in modular design any fundamental change leads to development of a new unit, if replacement of a component is not possible. Any clash brings about negative consequences, but a rational development of a modular unit taking into account specifics of engineering systems can help avoid clashes.

4. One of the fundamental issues is binding modular units together during installation. In traditional design, all assemblies have standard types. In modular design, development of effective combinations and ways of subsequent joint functioning of modular units is still at its primary level.

5.Due to a bigger size, volume and weight of modular units in comparison with existing construction units, on-site safety becomes even more important, as new input demands rethinking of labor safety requirements.

6. Preliminary detailed classification of construction and finishing works as offsite and onsite is necessary. The concept of completion of a modular unit assumes a rational (not $100 \%$ ) performance of works offsite. Degree of completion of a modular unit depends on many factors, including project purpose, climatic conditions and time of construction.

7.Design, construction management and logistics experts are facing new challenges relating to transportation, placement and storage of modular units, while traditional challenges become more complicated due to bigger sizes. More effective solutions require closer cooperation of architects and designers with logistics personnel to prevent future conflict situations.

8. It is practical to determine additional approvals and process owners, which is necessary for minimization of clashes at all levels.

Modular and traditional design processes have certain common aspects. However, fundamental differences are obvious. [21] Disadvantages of modular approach at the initial stages are later sufficiently compensated by advantages due to shorter time for completion and scope minimization. That said, all difficulties of modular design are mitigated with everyone new project due to expansion of the library, accumulation of experience and new knowledge, error checking.

\section{Results}

The paper helps to regard prefabrication design aspects from different points of view. Under the influence of modularity, it is possible to determine universal parameters of a complete modular unit and updated processes at all stages of a life cycle within the framework of modular design aspects and specific features of design processes, taking into account the three-level system of modular design principles.

It is also practical to represent the parameters of a complete modular unit in a three-level system that complies with the principles of modular design, and, at the same time, retains the properties of the modular element itself. (Table 1). 
Table 1. Complete modular unit parameters

\begin{tabular}{|c|c|c|c|}
\hline & \multicolumn{3}{|c|}{ Modular Design Principles } \\
\hline & Level I & Level II & Level III \\
\hline \multirow{4}{*}{ 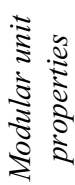 } & 1.1 Shape & 2.1 Functional profile & 3.1 Occupancy rate \\
\hline & 1.2 Sizes & 2.2 Placement & Climatic \\
\hline & 1.3 Design & (interior/exterior) & conditions \\
\hline & $\begin{array}{l}1.4 \text { Type of fastening } \\
\text { /line-up }\end{array}$ & $\begin{array}{l}2.3 \text { Construction } \\
\text { materials }\end{array}$ & $\begin{array}{l}3.3 \text { Transportation } \\
\text { complexity }\end{array}$ \\
\hline
\end{tabular}

Implementation of complete modular units is reflected at all stages of the life cycle of any construction project. Changes may arise both due to a new or modified design process, and due to compliance with the principles of modularity. New attributes affect the entire life cycle of a project in two ways: the direct effect at a specific stage and the universal effect at all stages of the life cycle simultaneously (Fig. 3).

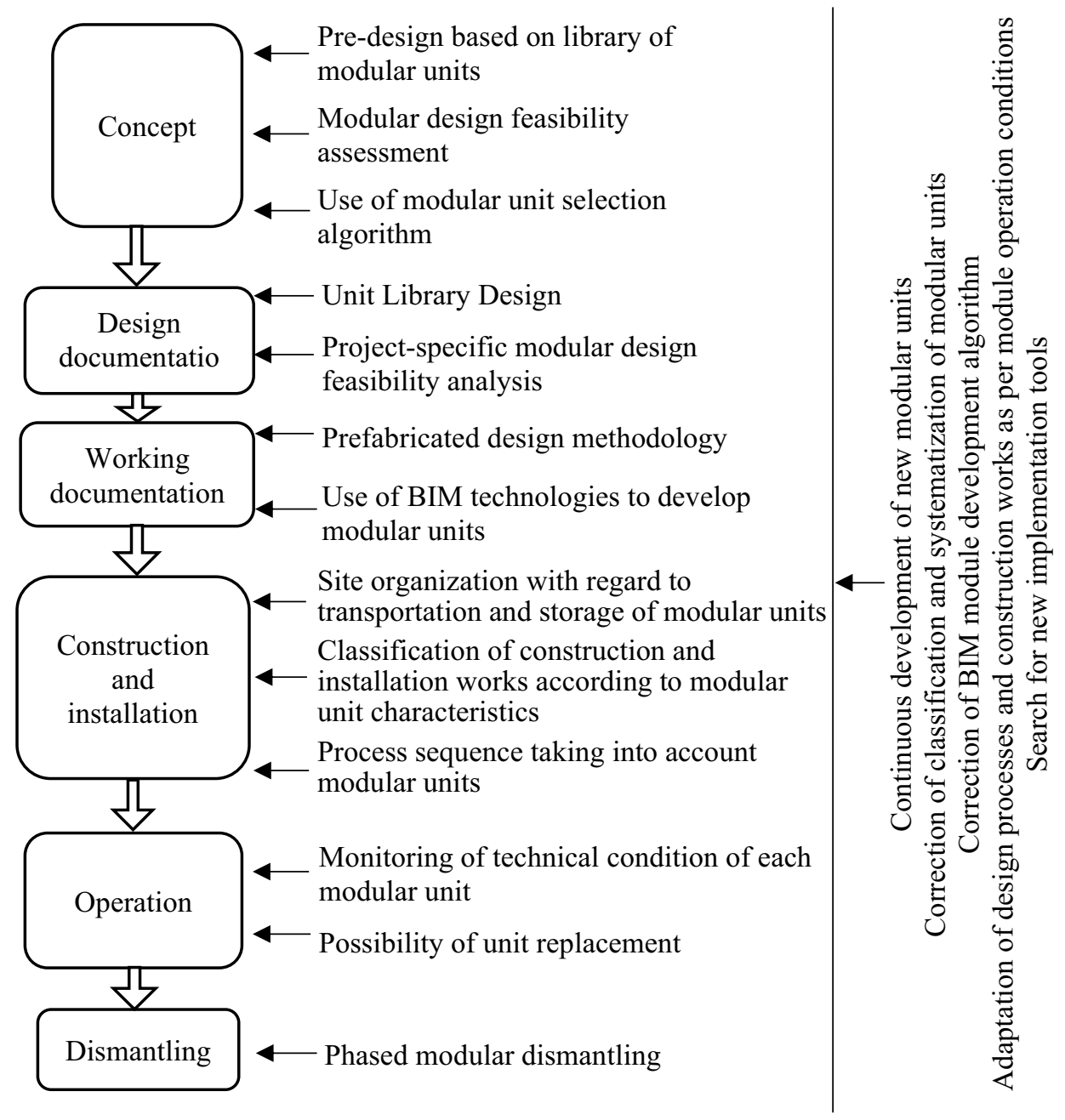

Fig. 3. Effect of modular attributes on the life cycle of a project 
Thus, prefabrication design is not only a new approach to design, but it also effects every stage of project life cycle. A detailed study of the modular principle based on complexities of its implementation gives birth to new rules, requirements, and methods of problem solving. Every feature of modularity leads to rationalizing effort in design, in one form or another. Based on advantages of using modular units, a total positive effect is formed for the entire life cycle of a project: faster design and construction, continuous improvement of quality of solutions used and works performed, application of advanced engineering techniques.

Problems in prefabrication design are temporary, due to the constant improvement of systematization, unit structure, and design algorithm. The modular principle gives birth to new directions of scientific research and development of new production technologies.

\section{Discussion}

The traditional design approaches do not guarantee a high quality level of design solutions. Besides, time of work completion is much longer. The current approach to expedite and rationalize construction is only partially effective, so a new integrated approach is needed that can significantly enhance performance through simultaneous improvement of several aspects. Prefabrication design can best fulfil this objective. The modular principle utilizes a number of new features, which ultimately have a positive effect on both design and construction.

Modular design includes both theoretical and practical aspects of implementation. The use of this approach implies development of new tools and ways to face new challenges, which are significantly different from the issues of traditional design.

\section{Conclusions}

Prefabrication design is one of the promising trends not only in engineering and construction, but also in scientific research. The state-of-the-art approach to design generates new methods to carry-out all types of work, and opens up development paths for professionals of all levels of expertise involved in construction. Existing software suites have a sufficient functionality for most efficient development of information models.

Analysis of traditional and modular design allows to distinguish undeniable advantages of modularity. The prefabrication design method serves as the foundation for further effective operation of a construction project, as well as for successful implementation of new projects.

The reported study was funded by RFBR, project number 20-37-90064.

\section{References}

1. A. Anton, L. Reiter, T. Wangler, V. Frangez, R.J. Flatt, B. Dillenburger, Automation in Construction, 122, 103467 (2021)

2. M. Arashpour, V. Kamat, Y. Bai, R. Wakefield, B. Abbasi, Automation in Construction, 95, 1-9 (2018)

3. Y. Gao, X.L. Tian, Journal of Cleaner Production, 122, 120042 (2020)

4. M. Goh, Y.M. Goh, Automation in Construction, 101, 227-244 (2019)

5. J. Han, D, Zhang, Q. Zhao, Architecture, 22 (2015)

6. B.G. Hwang, J. Ngo, Y. H. P. Wan, Journal of Cleaner Production, 262, 121396 (2020)

7. S. Jang, G. Lee, Automation in Construction, 89, 86-98 (2018) 
8. C. Kasperzy, M. Kim, I. Brilakis, Automation in Construction, 83, 184-195 (2017)

9. J. Lee, J. Kim, SUSTAINABILITY 9, 3, 426 (2017)

10. W. Lu, K. Chen, F. Xue, W. Pan, Journal of Cleaner Production, 201, 236-245 (2018)

11. Z. Lyu, P. Lin, D. Guo, G.Q. Huang, Robotics and Computer-Integrated Manufacturing, 64, 101932 (2020)

12. A. Mushinskiy, S. Zimin Construction of Unique Buildings and Structures 4, 31, 182193 (2015)

13. V. Naranje, R. Swarnalatha, Procedia Manufacturing, 32, 928-935 (2019)

14. F. Pittau, L. Malighetti, G. Iannaccone, G. Gabriele, Procedia Engineering, 180, 11601169 (2017)

15. A. Rybakova, P. Kagan, E3S Web of Conf., 97, 01008 (2019)

16. K. Zakharov, A. Galchenkov, S. Goldenberg, Information-analytical and intelligent systems in industry and the social sphere 64-77 (2019)

17. Y. Liu, M. Li, B.C.L. Wong, C.M. Chan, J.C.P. Cheng, V.J.L. Gan, Automation in Construction, 125, 103654 (2021)

18. J.L. Hao, B. Cheng, W. Lu, J. Xu, J. Wang, W. Bu, Z. Guo, Science of The Total Environment, 723, 137870 (2020)

19. S. Jang, G. Lee, Automation in Construction, 89, 123505 (2018)

20. R. He, M. Li, V.J.L. Gan, J.Ma, Journal of Cleaner Production, 278 (2021)

21. Y. Zhai, K. Chen, J.X. Zhou, J. Cao, Z. Lyu, X. Jin, G.Q.P. Shen, W. Lu, G.Q. Huang, Advanced Engineering Informatics, 42, 100997 (2019) 